\title{
Organizational Narcissism Scale (ONS)
}

\author{
Mehmet Ali Hamedoğlu ${ }^{1} \&$ Nihan Potas $^{2}$ \\ ${ }^{1}$ Faculty of Education, Sakarya University, Sakarya, Turkey \\ ${ }^{2}$ Faculty of Commerce and Tourism Education, Gazi University, Ankara, Turkey \\ Correspondence: Nihan Potas, University of Gazi, Faculty of Commerce and Tourism Education, University of \\ Gazi Gölbaşı Kampus, 06830 Gölbaşı, Ankara, Turkey. Tel: 9-506-437-9053. E-mail: nhnpotas@gmail.com
}

Received: May 12, 2012 Accepted: June 13, 2012 Online Published: July 11, 2012

doi:10.5539/emr.v1n2p53 URL: http://dx.doi.org/10.5539/emr.v1n2p53

\begin{abstract}
Narcissism is a kind of psychological case can be experienced by people or organizations with healthy or pathological dimensions. The goal of this work is to develop a scale for measuring organizational narcissism. This scale is developed in in two phases, and every dimension (leadership and authority, anticipation of recognition, grandiosity, self admiration and exhibition) of the scale strongly, positively correlates with the other dimensions, as well as with the scale as a whole. Test-retest process is used. To the first phase 762 managers and workers from small to mid-sized companies in various sectors have contributed to the second one the same group have participated and 718 of them answered. The validity and reliability analysis done by providing a reliable measurement tool, the scale will help determine whether organizational narcissism is healthy or pathological. It is ready to be used by the company managers who want to learn the narcissism level of their organizations.
\end{abstract}

Keywords: narcissism, organizational narcissism, scale

\section{Introduction}

\subsection{Importance and the Aim of the Study}

Narcissism is a kind of thing can be experienced in the organization as behavioral disorder or a personal aspect with different levels. To balance or utilize from these effects to know the level of organizational narcissism and its dimensions gain importance. This study become important with the scale it developed for being used in several studies. The aim of this paper is to develop a scale to measure organizational narcissism.

\subsection{Literature Review}

The concept of narcissism comes from the mythical story of Narcissus. According to the story, one day while on a hunt, Narcissus came across a calm and still stream. When he bent down to drink the water, he saw the beauty of his own face and body. He said to himself, "I am burning with self love. How can I reach this beauty which appears in the water? I cannot part from this image. Only death can save me." Narcissus then dies while observing his own reflection.

A narcissist is a person who generally feels a strong love for him/herself, finds him/herself magnificently important and feels a strong sense of authority. The American Psychiatric Association (2000) defines narcissism as a personality disorder found in various areas, which includes "a pervasive pattern of grandiosity, need for admiration and lack of empathy". The definition of the narcissistic personality disorder is somewhat vague, and is generally considered to be present when a series of egotistical behaviors are present, along with a positive identification by a clinician (APA, 2000, p. 717).

Narcissistic personalities have exaggerated egotistical feelings, in other words, feelings of self-importance. They chase goals like unlimited success, power, intelligence, beauty or immaculate love. They believe that they are special and unique, want to be liked and use interpersonal relations for their own gain. They do not hesitate to use other people's weaknesses for their own needs. They do not feel empathy, and usually think that others are jealous of them.

The extent to which all of these characteristics are present can be considered the level of a person's narcissism. For some, it might be possible to work with and adapt these characteristics so as to fit into society. Others are forcibly separated from the real world by their narcissistic characteristics. It is thus crucial to determine whether narcissism is healthy or extreme (pathological). This question, which is generally posed regarding individuals, will be explored in this work in terms of narcissism on an organizational level. 
According to Freud, individual psychology was developed and adapted for individual people. It has involved people trying to determine the motivations that lead to certain situations and states. However, figuring this out seldom involves straightforward conditions, when the relationships between individuals are taken into consideration. In an individual's psychological state, another person can be a model, an object, a helper or competition. Thus individual psychology is at the same time necessarily a question of societal psychology (Fromm, 2004a, p. 20).

When we look at the psychological reactions of a group, we must look at the group members' individual personality structures. But the interesting thing here is not how the differences between these people are produced, but rather the ways in which these personality structures can function together and create aspects of the group's total personality. This concept can be called "organizational personality". Organizational personality is necessarily less specific than individual personality, and is made up of only the fundamental core of the personality structures that emerge from the common experiences and lifestyles developed by an organization's members. There can also be "deviants" within the group who have personalities far different from the overall group personality. If we want to understand how human energy can be directed and organized, and how it functions in a certain societal order, we need to take a close look at organizational personality (Fromm, $1999 \mathrm{p}$. 258).

Narcissism might be discussed within organizational personality. Personality is made up of an individual's habitual behaviors, thoughts and feelings, ways of speaking and physical gestures. It is the predictable patterns in a person's manner of maintaining interpersonal relations and making decisions, either consciously or unconsciously (Volkan, 2005, p. 267).

The effective elements in personality development begin with childhood education and the methods used in raising a child. Education can prime an individual for the societal functions that he/she will play in the future. In other words, the person's personality is made up of the way the person will approach society, his/her hopes and the conflicts that will arise when he/she takes on a societal role. Educational methods do not lead to certain, clear societal personality structures, but are one of many mechanisms that form personality (Fromm, 1999, p. 265).

Depending on their personality structures, people might have a tendency to act in certain ways, but the environment in which they find themselves might not allow them to do what they wish to do. Organizations are in this way like individuals, and grow in an environment of changing conditions and individuals, in which ideas and reactions that come from the environment can affect the balance of the personality that emerges. Organizations must adapt to various conditions, as well as the organizational goals and the expectations of other individuals, and they develop personality characteristics that allow them to do this. Like people, organizations are motivated to protect their own collective personality and validity (Brown, 1997, p. 683; Ganesh, 2003, p. 558; Fromm, 1999, p. 259). They develop belief systems and cultures that help members understand how they should behave, who should be part of the collective and what they need to become (Whetten, 2006, p. 219).

Members of an organization develop their personalities not just based on what others say about them, but also how others perceive them. Dutton and Dukerich (1991) take the Port Transport Company as an example. The port workers did not accept the view that others had about them, and attempted to change this perception. They did this in particular by working with the feelings that emerged when faced with other people's views that were in conflict with what they saw in the mirror, and thus took it upon themselves to redefine their organizational culture (Dutton \& Dukerich, 1991, p. 554). Cultures, by overcoming uncertainties, allow for the development of defense mechanisms for preserving personalities (Duchon \& Drake, 2007, p. 2). This narcissistic reaction is another coping mechanism for protecting and taking care of the organization's personality. Attempts like this to protect personality are necessary for the organization's continued existence, and should generally be desirable. The personality of an organization takes on a clearer form when ways are found to solve harmony and integration problems, and displaying fundamental and constant characteristics that make up a personality (Schein, 1992, p. 4). These defense mechanisms, as in individuals, can also emerge as pathological narcissistic reactions, which pull the organization away from reality and involve efforts to fuel vanity and delusions of grandeur, rather than adding something valuable to the organization's vital characteristics, which would be a healthy product of organizational narcissism.

Organizational narcissism might be healthy or pathological. When an organization's members are motivated to protect a self image that reflects their social categories and is a part of them, they collectively move to set up a certain level of self respect for the organization. The organization does this in order to be able to use ego-defending behaviors to create self-respect, not just for protecting people, but also for raising the validity of the collective category (Brown, 1997, p. 650). This situation allows us to see the reflection of individual 
narcissism on an organization. Just like individuals who develop narcissistic characteristics that protect their ego, organizations can do the same.

As with individuals, healthy narcissism can raise the performance of an organization. Talented narcissists are often highly intelligent, and can combine their grandiosity, self investment and fantasy to be successful in academic and professional circles (Maccoby, 2003; Ronningstam, 2005, p. 79). They face social pressures with decisiveness, and to reach goals they show tireless effort in turning situations toward their own benefit. They are self-confident, focused on power, and able to use these qualities to improve the effectiveness of an organization or its quality of life (Duchon \& Burns, 2008, p. 643-644). In this sense, organizations can increase their success by adopting narcissistic characteristics.

Healthy narcissistic characteristics depend on individuals having positive relationships with organizations, and increasing their egotistical respect to include both themselves and the organization. By dealing with the good and bad situations that arise with regard to the organization as if they were happening to themselves, they can help the organization reach its goals.

Hatch and Schultz (2002) use the model they developed for organizational personality to look at organizational narcissism (self-centeredness) and how this personality can have a negative function (Hatch \& Schultz, 1997, p. 356). Self-centered organizations have very specific definitions and ideas about themselves and their borders, and in this narrow field they attempt to work for personal profit. A self-centered understanding of personality can lead to two negative results: maintaining an unrealistic personality, or creating personalities that will destroy important elements of the context in which one finds oneself.

Creating an extremely narcissistic personality is a problem that feeds itself. An extremely narcissistic organizational personality can create a tendency to try to make the organization seem right and correct at any price (Brown, 1997, p. 683). Organizations that are subject to extreme narcissism lose their ability to perceive real situations and are plagued by lies that damage their personalities, self-aggrandizement and delusions of grandeur.

Extremely narcissistic organizations are void of empathy, and see the opportunity for success in the exploitation of others. They put extreme emphasis on continued success, using people as resources that they can completely exploit, and act even at the expense of other organizational services. Such a personality can be a sign either of high self respect or low self respect. Usually an organization with high self respect is characterized by an exaggerated egotism and is blind to its own weaknesses. An organization that is ready to exploit itself cannot maintain credibility, and the advantages of internal competition turns to disadvantages (Duchon \& Burns, 2008, p. 355). If an organization is extraordinarily proud, its current successes and major hopes might correspond to its future successes. Leaders in these organizations will see very few limitations regarding what can be accomplished and what goals can be reached. Feelings of entitlement can support the exploitation of others, including customers and the broader public. The mental state of such an organization cannot be predicted-one day a major success might be celebrated, and a week later a small goal that could not be met might lead to extreme sadness. Some people in the organization might be insulated from the rest, and this group's preferred leaders might form secret groups. The organization will be less interested in serving the people, and more interested in proving the legitimacy of its existence (Brown, 1997, p. 644).

Organizational narcissism analysis is in the tradition of psycho-analysis, and involves adapting the narcissistic characteristics that individual personalities can display to organizational behaviors. Raskin and Terry developed the narcissistic personality scale to measure individual narcissism, and it has become one of the most widely-used tools for this purpose. In this scale narcissism is made up of the sub-dimensions of authority, exhibitionism, superiority, arrogance, exploitation, self-righteousness and self-satisfaction (Raskin \& Terry, 1988). The narcissistic personality scale used by Emmons (1987) is made up of 4 sub-dimensions, which are Leadership/Authority, Egotism, Superiority/Arrogance and Exploitation/Righteousness (Tschanz, Morf, \& Turner, 1998). In another, more recent study, Raskin and Terry use a 54-item scale, and after removing items with weak factor loads based on a factor analysis, they reduced the scale to 40 items. In the study, the strongest three sub-dimensions were power, exhibitionism and being special (Kubarycha, Dearyb, \& Austin, 2004).

\subsection{Research Questions}

The question of this study is "Would an organizational narcissism scale be developed with high validity and reliability?". This work is designed to find an answer to this question.

\section{Methodology}

Data collection tools that are ready to be applied require two fundamental properties, "validity and reliability". Validity tests to what extent the property you are trying to test is actually being tested, while reliability involves consistency in how individuals answer the items (Colton \& Covert, 2007, pp. 65-93). 
In order to test the consistency of the tool over time, the test-retest method was used. There was a 3-month period between the test and the retest. Thus, the study had two phases.

\subsection{Participants}

In the first phase the scale was applied to a total of 762 managers and workers from small to mid-sized companies in various sectors. For the second phase it was reapplied to the same people 6 months later. Since not all 762 of these people could be reached, the test was carried out on 718 people. This is a self existing sample.

\subsection{Research Design}

Research is designed as two phases.

\section{Phase}

In this phase, a literature review was carried out to check scope validity. We looked at Raskin and Terry's 1988 individual narcissism scale, and the items that could be applied to organizations were identified. Later, after adding various items from the literature review to the scale, a pool of 56 items was created. Expert advice was taken regarding the scale, and items that were seen as too similar to other items, or irrelevant, were removed, leaving 38 items in the final scale.

Once the 38-item organizational narcissism scale was subjected to a factor analysis, 4 items (3.10.14.36) were found to have very low factor loads, each of which was below 0.4 , were removed from the scale. Thus the scale was reduced to 34 items. Another factor analysis showed that the items could be separated into 5 sub-dimensions: grandiosity, self-admiration and vanity, leadership and authority, anticipation of recognition and exhibitionism. An explanatory factor analysis (EFA) and corrective factor analysis (CFA) were applied for validity and reliability.

Structure Validity: An Explanatory Factor Analysis (EFA) is a multi-variable statistical factor analysis. Its goal is to reduce $\mathrm{k}$ variables (the items) to $\mathrm{r}$ independent dimensions. For the suitahility of the data to a factor analysis, statistical results of $\mathrm{KMO}$ and Bartlett tests were calculated $\left(\mathrm{KMO}=0,893 ; \chi^{2}=9703,3 \mathrm{p}<0,05\right)$. According to these results, the data and the sample were determined to be suitable for a factor analysis. In the factor analysis, the fundamental factors method was used, and a rotation was carried out using the Varimax method and Kaiser normalization. The result of the factor analysis was 38 items in 5 sub-dimensions, with a total variance ratio of $62.6 \%$.

Table 1. Factor loads of the organizational narcissism scale rotated component matrix(a)

\begin{tabular}{|c|c|c|c|c|c|}
\hline \multirow{2}{*}{$\begin{array}{l}\text { Item } \\
\text { Number }\end{array}$} & & 1 & 2 & 4 & 5 \\
\hline & Item & 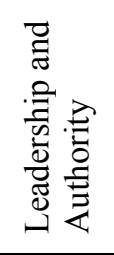 & 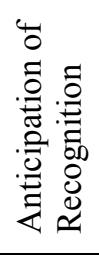 & 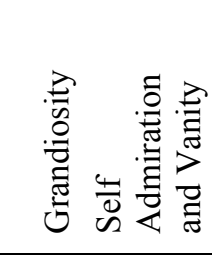 & 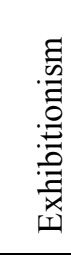 \\
\hline 29 & Other companies are no match for us. & 0.764 & & & \\
\hline 26 & $\begin{array}{l}\text { Our company is a source of inspiration for } \\
\text { all other organizations. }\end{array}$ & 0.715 & & & \\
\hline 28 & Our company is a leader in its category. & 0.699 & & & \\
\hline 20 & $\begin{array}{l}\text { At meetings and in other situations our } \\
\text { company is the focus of attention. }\end{array}$ & 0.689 & & & \\
\hline 8 & Our company is the center of attention. & 0.667 & & & \\
\hline 11 & Those who dislike us are blind. & 0.636 & & & \\
\hline 33 & $\begin{array}{l}\text { Other organizations should take us as an } \\
\text { example. }\end{array}$ & 0.630 & & & \\
\hline 32 & We are very successful. & 0.605 & & & \\
\hline 27 & $\begin{array}{l}\text { One day, everyone will be talking about our } \\
\text { successes. }\end{array}$ & 0.562 & & & \\
\hline 25 & We start new things. & 0.500 & & & \\
\hline 31 & We have the best staff. & 0.494 & & & \\
\hline 1 & Everyone likes hearing our story. & 0.434 & & & \\
\hline 17 & When I introduce myself I also say where I & & 0.723 & & \\
\hline
\end{tabular}




\begin{tabular}{llll}
\hline \multicolumn{5}{l}{ work. } & & \\
\hline 18 & I would say that I am proud of where I work. & 0.674 & \\
\hline 6 & We have an atmosphere that affects people. & 0.669 & \\
\hline 7 & We know how valuable we are. & 0.618 & \\
\hline 12 & $\begin{array}{l}\text { Our company has a very nice working } \\
\text { environment. }\end{array}$ & 0.601 & \\
& $\begin{array}{l}\text { Our company has its own, unique, very nice } \\
\text { image. }\end{array}$ & 0.600 & \\
\hline 15 & There is nothing we can't succeed in. & 0.491 & 0.807 \\
\hline 23 & We are always aware of what we are doing. & 0.714 & \\
\hline 34 & There is nothing we can't do. & 0.549 & \\
\hline 30 & We never give up before succeeding. & 0.514 & \\
\hline 35 & It is impossible to ignore our success. & 0.509 & \\
\hline 37 & $\begin{array}{l}\text { Not being taken into account by our peers } \\
\text { makes us angry. }\end{array}$ & & 0.781 \\
\hline 9 & We should definitely take part in activities. & 0.563 \\
\hline 2 & There is no one who doesn't know us. & 0.562 \\
\hline 4 & $\begin{array}{l}\text { We make a difference at meetings and } \\
\text { activities. }\end{array}$ & & 0.544 \\
\hline 24 & We are a very picky company. & 0.541 \\
\hline 5 & I like when other people praise us. & 0.527 \\
\hline 19 & A book should be written about us. & & \\
\hline 21 & We organize great ceremonies. & 0.905 \\
\hline 22 & We organize unbelievably nice festivities. & 0.905 \\
\hline 38 & $\begin{array}{l}\text { We put our successes on display in a striking } \\
\text { manner. }\end{array}$ & & 0.846 \\
\hline 13 & $\begin{array}{l}\text { An important part of our budget goes toward } \\
\text { advertising. }\end{array}$ & & 0.843 \\
\hline 16 & & & \\
\hline
\end{tabular}

Rotated

Sums of

Squared

Loadings \%of

Variance

TOTAL: $62.649 \%$

$20.787 \% \quad 14.08 \% \quad 11.765 \% \quad 8.434 \% \quad 7.584 \%$

According to Table 1. the result of the factor analysis was 5 sub-dimensions, the first of which was leadership and authority. It is made up of 12 items, its variance explanation ratio is $20.8 \%$, and the factor load of its items varied between 0.765 and 0.434 .

The second sub-dimension was "anticipation of recognition", and is made up of 7 items. The variance explanation ratio of this dimension is $14.08 \%$. The items' factor loads vary between 0.723 and 0.491 .

The third dimension "grandiosity" is made of 5 items. This sub-dimension's explanation ratio is $11.765 \%$. Its items' factor load varies between 0.807 and 0.509 .

The fourth sub-dimension is "self-admiration and vanity", which is made up of 6 items. Its variance explanation ratio is $8.434 \%$. Its items' factor loads varied between 0.781 and 0.572 .

The fifth and final sub-dimension is "exhibitionism" and is made of 4 items. Its items' factor loads vary between 0.905 and 0.843 . The item loads were highest in this sub-dimension. The dimension's variance explanation ratio is $7.584 \%$.

\section{Reliability}

We looked at the Cronbach alpha to calculate the reliability of the scale. The Cronbach alpha coefficient indicates both whether the items are measuring the same. thing, and also what their relationship to each other is. According to Streiner DL (2003), if the Cronbach alpha is greater than 0.9, the measure is excellent, if it is between 0.9 and 0.8 , it is good, if it is between 0.8 and 0.7 , it is acceptable, if it is between 0.7 and 0.6 , it is questionable, 0.6 to 0.5 is poor and under 0.5 is unacceptable. 
Table 2. The cronbach alpha values of the organizational narcissism scale

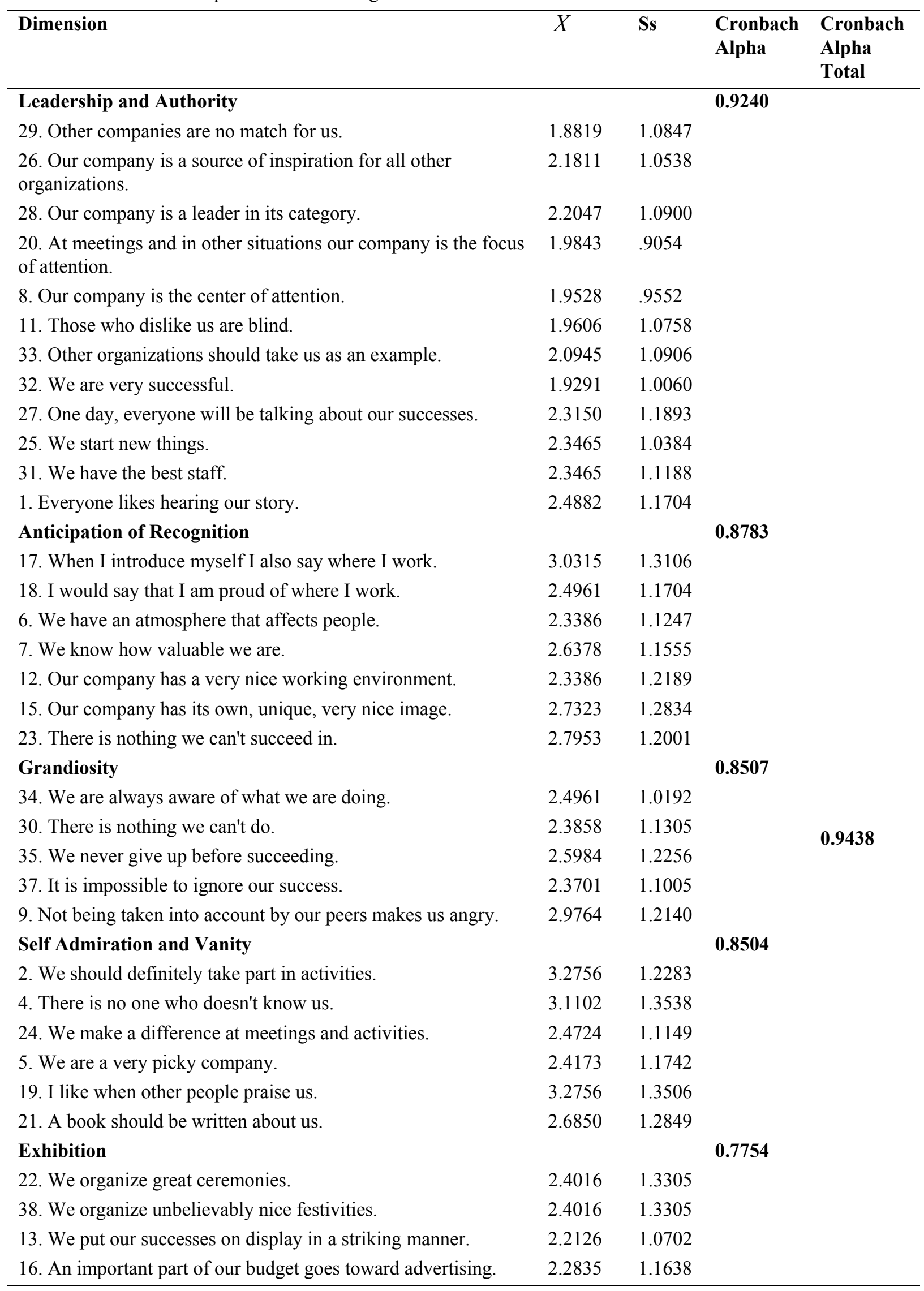


According to Table 2 the results of this test were that the general tool is at an "excellent" level, the Leadership and Authority is "excellent", Anticipation of Recognition, Grandiosity and Self Admiration and Vanity dimensions are "good" and the Exhibition dimension is at an acceptable level. The alpha coefficients of the dimensions are high enough that they can be considered acceptable (Yurdugül, p. 7)

For the validity of the organizational narcissism scale, we looked at the total correlation of the items.

Table 3. Total item correlation of the organizational narcissism scale

\begin{tabular}{|c|c|c|c|c|c|}
\hline & $\begin{array}{c}\text { Total of } \\
\text { Organizational }\end{array}$ & & & $\begin{array}{c}\text { Total of } \\
\text { Organizational }\end{array}$ & \\
\hline Item & Narcissism & & Item & Narcissism & \\
\hline Number & $\mathrm{r}$ & $\mathrm{P}$ & Number & $\mathrm{r}$ & $\mathrm{P}$ \\
\hline 1 & $.517(* *)$ & 0.00 & 21 & $.544(* *)$ & 0.00 \\
\hline 2 & $.409(* *)$ & 0.00 & 22 & $.568(* *)$ & 0.00 \\
\hline 4 & $.353(* *)$ & 0.00 & 23 & $.625(* *)$ & 0.00 \\
\hline 5 & $.797(* *)$ & 0.00 & 24 & $.580(* *)$ & 0.00 \\
\hline 6 & $.628(* *)$ & 0.00 & 25 & $.743(* *)$ & 0.00 \\
\hline 7 & $.749(* *)$ & 0.00 & 26 & $.769(* *)$ & 0.00 \\
\hline 8 & $.716(* *)$ & 0.00 & 27 & $.782(* *)$ & 0.00 \\
\hline 9 & $.530(* *)$ & 0.00 & 28 & $.711(* *)$ & 0.00 \\
\hline 11 & $.679(* *)$ & 0.00 & 29 & $.615(* *)$ & 0.00 \\
\hline 12 & $.728(* *)$ & 0.00 & 30 & $.594(* *)$ & 0.00 \\
\hline 13 & $.699(* *)$ & 0.00 & 31 & $.670(* *)$ & 0.00 \\
\hline 15 & $.582(* *)$ & 0.00 & 32 & $.703(* *)$ & 0.00 \\
\hline 16 & $.335(* *)$ & 0.00 & 33 & $.665(* *)$ & 0.00 \\
\hline 17 & $.678(* *)$ & 0.00 & 34 & $.701(* *)$ & 0.00 \\
\hline 18 & $.744(* *)$ & 0.00 & 35 & $.753(* *)$ & 0.00 \\
\hline 19 & $.530(* *)$ & 0.00 & 37 & $.778(* *)$ & 0.00 \\
\hline 20 & $.620(* *)$ & 0.00 & 38 & $.568(* *)$ & 0.00 \\
\hline
\end{tabular}

According to Table 3. the total item correlation in the organizational narcissism scale varies between 0.335 and 0.782. All of the items in the scale can be seen to be correlated with the total scale.

Table 4. Correlation between the dimensions in the organizational narcissism scale and the general scale

\begin{tabular}{ccc}
\hline Sub-Dimensions & Total of Organizational Narcissism & $\mathrm{P}$ \\
\cline { 2 - 3 } & $\mathrm{N}=762$ & \\
\hline Leadership and Authority & $.922\left(^{* *}\right)$ & 0.00 \\
Anticipation of Recognition & $.887\left(^{* *}\right)$ & 0.00 \\
Grandiosity & $.844\left(^{* *}\right)$ & 0.00 \\
Self Admiration and Vanity & $.788\left(^{* *}\right)$ & 0.00 \\
Exhibitionism & $.757\left(^{* *}\right)$ & 0.00 \\
\hline
\end{tabular}

$\mathrm{p}^{* *}<0.01$

The relationship between each dimension and the general scale is positive and strong. All of the dimensions are correlated with the total scale. 


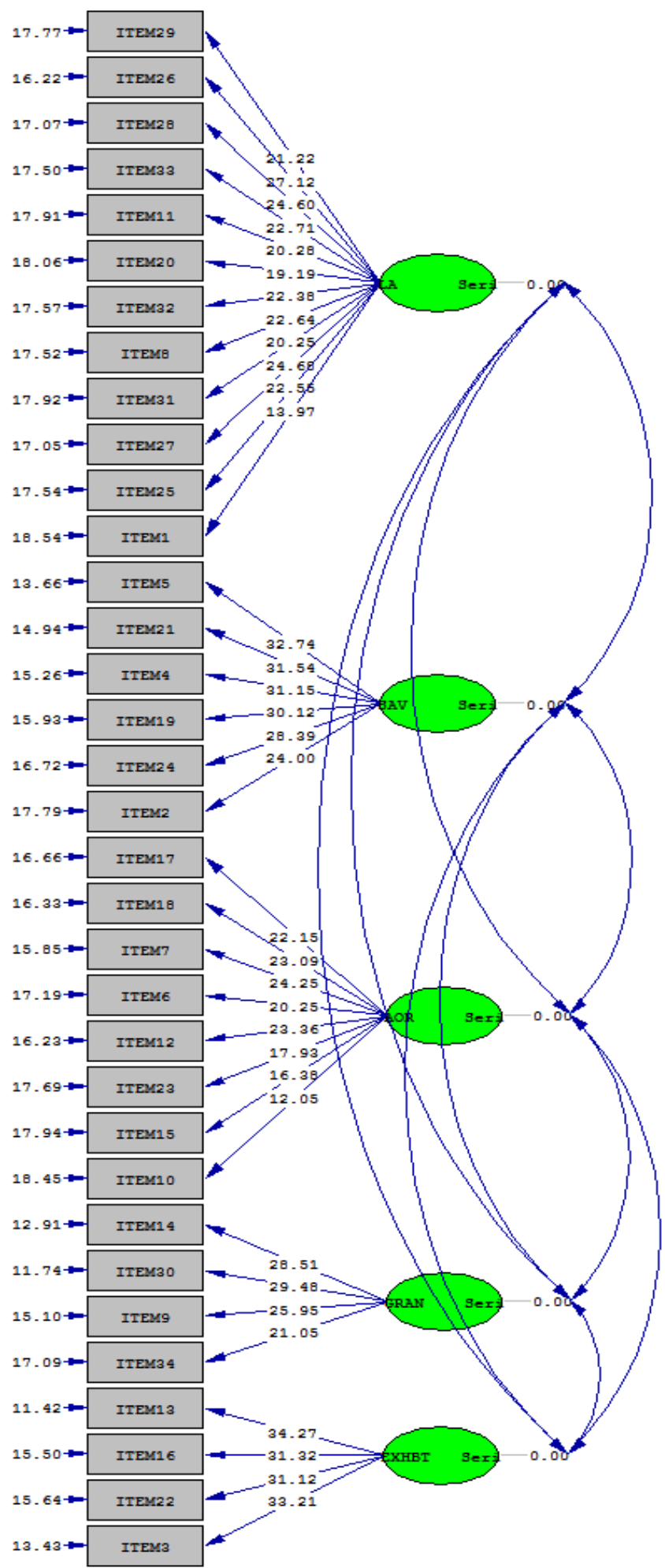

Figure 1. Path diagram and factor loads of the organizational narcissism scale

LA = Leadership and Authority

$\mathrm{SAV}=$ Self Admiration and Vanity

AOR=Anticipation of Recognition

GRAN $=$ Grandiosity

EXHBT $=$ Exhibitionism 
Confirmative Factor Analysis: Confirmative Factor Analysis is a "structural equality analysis" in statistics. It is a method used for confirming possible relations between variables, and later testing structural equality. In other words, its goal is to test how well our hypotheses fit to the sample of data we have collected. The path analysis tests one or more models of the cause and effect relations in the confirmative factor analysis. As descriher above, the goal is to test the model in terms of the data (Şimşek, 2007, p. 1,11). The model's compatibility is $\left(\chi^{2}=3082\right.$, $17 ; p<0,05)$. This is a sign of high compatibility.

In the corrective factor analysis, RMSEA is a coefficient of fit. If this value is below 0.05 , the fit is good, if it is between 0.05 and 0.08 , it is acceptable, and if it is between 0.08 and 0.10 it is weak. If it is higher, the fit is unacceptable (Schuwacker and Lomax, 2004). The RMSEA value for the organizational narcissism scale is 0.073. This shows that the fit is acceptable.

\section{Phase}

The second phase is intended as a test of what was carried out in the first phase. In this phase, the test, which was reduced to 34 items,. The scale was once again subjected to a factor analysis, and as in the first phrase, it was seen that the items could be grouped into five dimensions. When the second phase began, the numbers assigned to the items were reorganized.

Table 5. The factor loads of the organizational narcissism scale (retest)

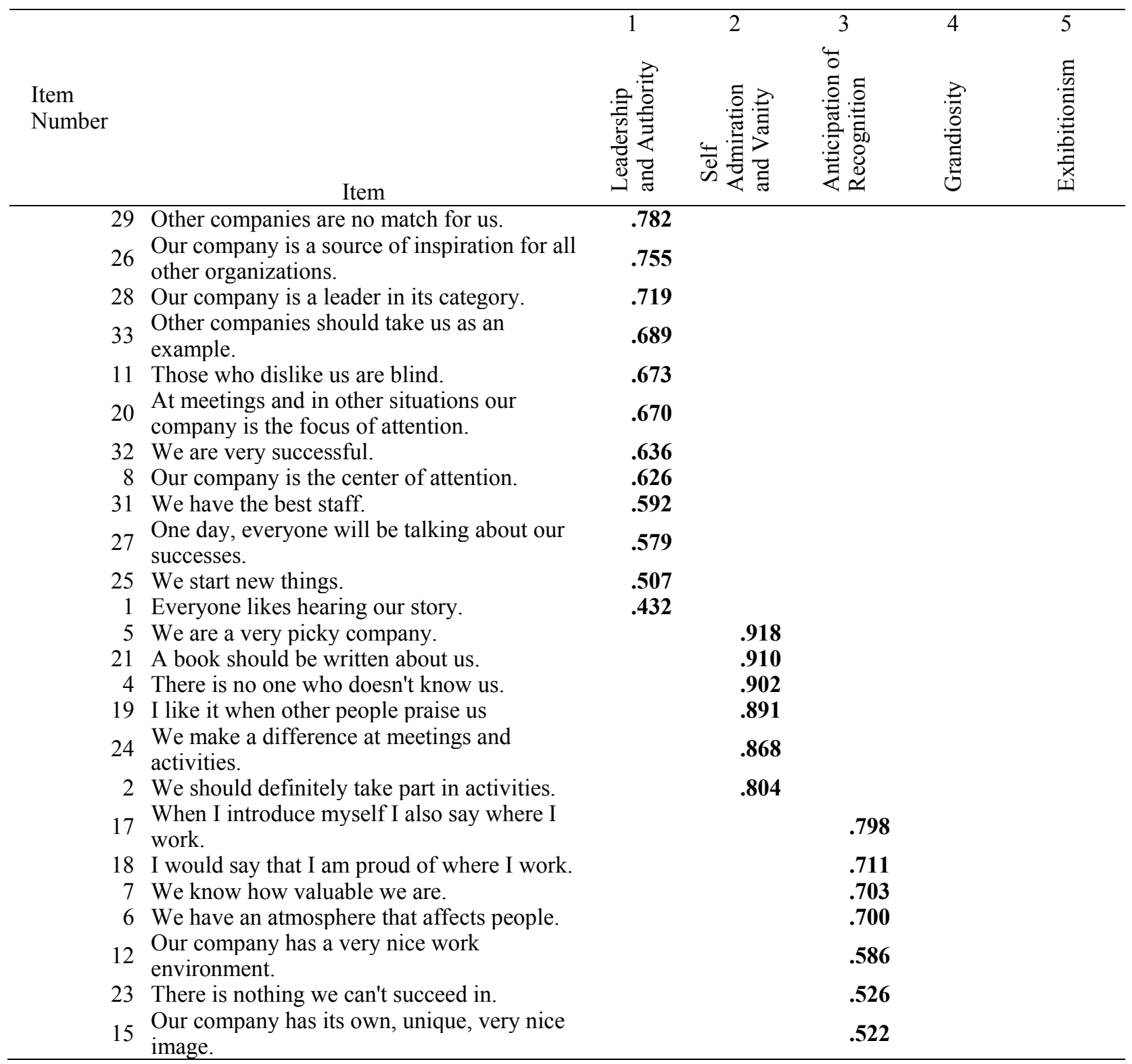


10 It is impossible to ignore our success.

.883

.860

14 We never give up before succeeding.

.855

30 There is nothing we can't do.

.823

makes us angry.

.612

34 We are always aware of what we are doing.

13 We put our successes on display in a striking manner.

3 We organize unbelievably nice festivities.

16 An important part of our budget goes toward advertising.

22 We organize great ceremonies.

Rotated

Sums of

Squared

TOTAL: $68.997 \%$

$18.14 \% \quad 14.672 \% \quad 12.865 \%$

$12.287 \%$

$11.034 \%$

of Variance

According to table 5, the total variance explanation ratio of the re-tested organizational narcissism scale is $69 \%$. The "Leadership and Authority" sub-dimension, made of 12 items, has a factor load that varies between 0.782 and 0.432 . The variance explanation ratio is lower than in the previous phase, and has a value of $18.14 \%$.

The second sub-dimension, made up of 6 items, was "self-administration and vanity", and has a factor load that varies between 0.918 and 0.804 . The variance explanation ratio was higher than previously, at $14.672 \%$

The third sub-dimension, "anticipation of recognition was made up of 7 items. Its variance explanation ratio is $12.627 \%$. This was lower than previously. Its items' factor loads vary between 0.798 and 0.522 .

The fourth sub-dimension, made of 5 items, was "grandiosity". Its variance explanation ratio is $12.287 \%$. This was higher than previously. Its items have a factor load that varies between 0.883 and 0.612 .

The fifth and final sub-dimension, "exhibitionism” is made up of 4 items, and its factor loads vary between 0.899 and 0.876 . Its variance explanation ratio is $11.034 \%$, which is higher than previously.

Table 6. Cronbach alpha values for organizational narcissism scale (retest)

\begin{tabular}{lllll}
\hline Dimension & $X$ & Ss & $\begin{array}{l}\text { Cronbach } \\
\text { Alpha }\end{array}$ & $\begin{array}{c}\text { Cronbach Alpha } \\
\text { Total }\end{array}$
\end{tabular}

\section{Leadership and Authority}

29. Other companies are no match for us.

26. Our company is a source of inspiration for all other organizations.

28. Our company is a leader in its category.

33. Other organizations should take us as an example.

11. Those who dislike us are blind.

20. At meetings and in other situations our company is the focus of attention.

32. We are very successful.

8. Our company is the center of attention.

31. We have the best staff.

27. One day, everyone will be talking about our successes.

25. We start new things.

1. Everyone likes hearing our story.

Anticipation of Recognition

17. When I introduce myself I also say where I work.

18. I would say that I am proud of where I work.

6 . We have an atmosphere that affects people.

7. We know how valuable we are.

\section{$\mathbf{0 . 9 2 4 3}$}

$1.9053 \quad 1.0885$

$2.1992 \quad 1.0553$

$2.2201 \quad 1.0857$

$2.1184 \quad 1.0958$

$1.9875 \quad 1.0817$

$\begin{array}{ll}1.9986 & 0.9094\end{array}$

$1.9485 \quad 1.0139$

$1.968 \quad 0.9625$

$2.3621 \quad 1.1178$

$\begin{array}{ll}2.3426 & 1.1961\end{array}$

$2.3719 \quad 1.0428$

$2.5014 \quad 1.1652$

$3.0585 \quad 1.3148$

$2.4958 \quad 1.1948$

$2.3593 \quad 1.1274$

$2.6616 \quad 1.1576$

$2.3691 \quad 1.228$

\subsection{0}

\subsection{4}


environment.

23. There is nothing we can't succeed in.

15. Our company has its own, unique, very nice image.

\section{Grandiosity}

10. It is impossible to ignore our success.

9. Not being taken into account by our peers makes us angry.

30. There is nothing we can't do.

34. We are always aware of what we are doing.

14. We never give up before succeeding.

Self Admiration and Vanity

2. We should definitely take part in activities.

4. There is no one who doesn't know us.

24. We make a difference at meetings and activities.

5 . We are a very picky company.

19. I like when other people praise us.

21. A book should be written about us.

\section{Exhibition}

22. We organize great ceremonies.

13. We put our successes on display in a striking manner.

16. An important part of our budget goes toward advertising.

3. We organize unbelievably nice festivities.

$\begin{array}{lll}2.8259 & 1.2028 & \\ & & \\ 2.7549 & 1.2909 & \\ & & \mathbf{0 . 9 2 2 8} \\ 2.4749 & 1.1887 & \\ & & \\ 2.4318 & 1.1799 & \\ 2.4972 & 1.1712 & \\ 2.5237 & 1.018 & \\ 2.4847 & 1.1711 & \\ & & \mathbf{0 . 9 4 0 8} \\ 3.2423 & 1.2979 & \\ 3.2382 & 1.26 & \\ 3.2368 & 1.2619 & \\ 3.2618 & 1.2469 & \\ 3.2159 & 1.2618 & \\ 3.2786 & 1.2478 & \\ & & \mathbf{0 . 9 4 9 0} \\ 2.4708 & 1.2855 & \\ & & \\ 2.4485 & 1.3442 & \\ & & \\ 2.4791 & 1.3231 & \\ 2.4025 & 1.2962 & \\ & & \\ & \end{array}$

In the re-applied test, "anticipation of recognition" stayed the same, and the other dimensions rose to "excellent".

Table 7. Total item correlation for organizational narcissism scale

\begin{tabular}{|c|c|c|c|c|c|}
\hline \multirow{2}{*}{$\begin{array}{c}\text { Item } \\
\text { Number }\end{array}$} & \multicolumn{2}{|c|}{ Retest } & \multirow{2}{*}{$\begin{array}{c}\text { Item } \\
\text { Number }\end{array}$} & \multicolumn{2}{|c|}{ Retest } \\
\hline & $\mathrm{r}$ & $\mathrm{p}$ & & $\mathrm{r}$ & $\mathrm{p}$ \\
\hline 1 & $.499(* *)$ & 0.00 & 18 & $.672(* *)$ & 0.00 \\
\hline 2 & $.316(* *)$ & 0.00 & 19 & $.350(* *)$ & 0.00 \\
\hline 3 & $.495(* *)$ & 0.00 & 20 & $.611(* *)$ & 0.00 \\
\hline 4 & $.354(* *)$ & 0.00 & 21 & $.357(* *)$ & 0.00 \\
\hline 4 & $.369(* *)$ & 0.00 & 22 & $.490(* *)$ & 0.00 \\
\hline 6 & $.655(* *)$ & 0.00 & 23 & $.601(* *)$ & 0.00 \\
\hline 7 & $.749(* *)$ & 0.00 & 24 & $.330(* *)$ & 0.00 \\
\hline 8 & $.694(* *)$ & 0.00 & 25 & $.749(* *)$ & 0.00 \\
\hline 9 & $.477(* *)$ & 0.00 & 26 & $.737(* *)$ & 0.00 \\
\hline 10 & $.535(* *)$ & 0.00 & 27 & $.778(* *)$ & 0.00 \\
\hline 11 & $.658(* *)$ & 0.00 & 28 & $.695(* *)$ & 0.00 \\
\hline 12 & $.709(* *)$ & 0.00 & 29 & $.584(* *)$ & 0.00 \\
\hline 13 & $.501(* *)$ & 0.00 & 30 & $.530(* *)$ & 0.00 \\
\hline 14 & $.517(* *)$ & 0.00 & 31 & $.658(* *)$ & 0.00 \\
\hline 15 & $.588(* *)$ & 0.00 & 32 & $.688(* *)$ & 0.00 \\
\hline 16 & $.493(* *)$ & 0.00 & 33 & $.659(* *)$ & 0.00 \\
\hline 17 & $.644(* *)$ & 0.00 & 34 & $.669(* *)$ & 0.00 \\
\hline
\end{tabular}

According to Table 7 the correlations among the total items are thus still intact. 
Table 8. Correlations of dimensions with total scale (retest)

\begin{tabular}{ccc}
\hline Sub-Dimensions & Total of Organizational Narcissism & $\mathrm{P}$ \\
& $\mathrm{N}=762$ & \\
\hline Leadership and Authority & $.903\left(^{* *}\right)$ & 0.00 \\
Anticipation of Recognition & $.86\left(^{* *}\right)$ & 0.00 \\
Grandiosity & $\left..681^{* *}\right)$ & 0.00 \\
Self Admiration and Vanity & $.737\left(^{* *}\right)$ & 0.00 \\
Exhibitionism & $.666\left(^{* *}\right)$ & 0.00 \\
\hline
\end{tabular}

According to Table 8 in the reapplied scale, all of the dimensions still fit to one another.

Table 9. The correlation coefficients between the $1^{\text {st }}$ and $2^{\text {nd }}$ applications of the organizational narcissism scale

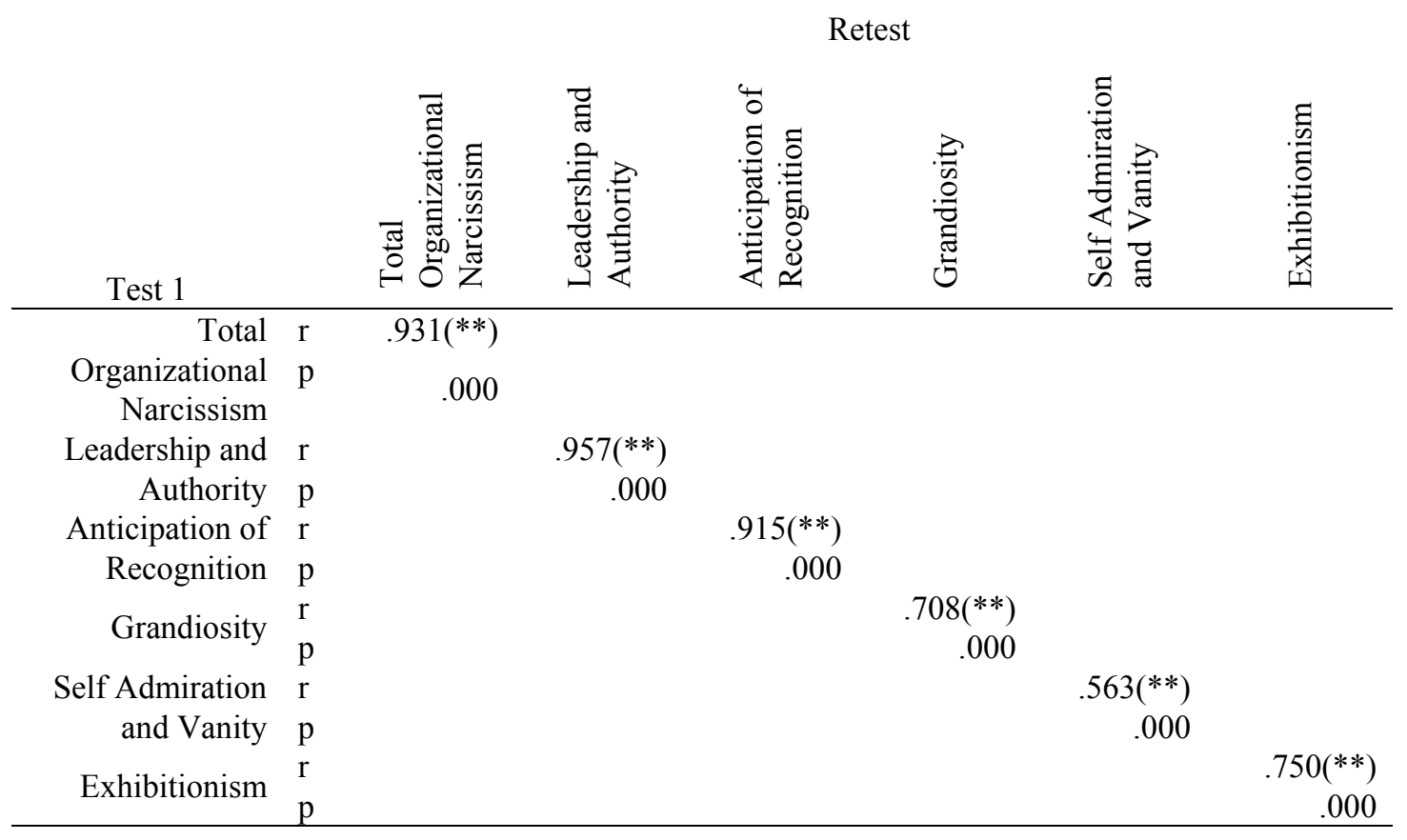

When we compare the results of first and second applications according to Table 9, both the general scale and all sub-dimensions are at a high level. The level of the relations for "Leadership and Authority" and "Anticipation of Recognition" are higher than the other relations.

\section{Results}

In this study to create a validity and reliable scale following process is followed;

In the first phase the scale with 38 items is applied. Explanatory factor analysis (EFA) and corrective factor analysis (CFA) are done. At the end 4 items removed because of the low factor loads. For reliability cronbach alpha values are looked and with the values from 0,7754 to 0,9240 all dimensions and total found related. Item correlations from 0,335 to 0,782 showed all items are correlated with all scale. Confirmative factor analysis showed that the fit is acceptable.

In the second phase to understand the new scale' validity and reliability factor loads are calculated. No new items found to be removed. New cronbach alpha values change from 0,949 to 0,8740 . All items found highly related with organizational narcissism scale. All dimensions are related (from 0,957 to 0,563 ) with the all scale.

The conclusions reached in this study have allowed us to observe and measure the definitions we have been working with for organizational narcissism, as well as to look at how each of the sub-dimensions interact with, overlap with and lead to the creation of the others. At the same time, the organizational aspects of narcissism have been brought to the forefront. The scale that has been developed is ready to be used. Testing whether the 
scale can also be applied successfully in other cultures and societies will be a significant contribution to both theory and practice in the fields of organizations and management.

\section{Discussion}

In the changing world narcissistic features seem like shaping the companies and realizing these features and utilize or prevent from the effects will be important. Measuring the level of the organizational narcissism will become a need for the organizations. And with its high values and its fitting structure to various companies the "organizational narcissism scale (ONS)" is waited to be useful for various companies.

\section{References}

Brown, A. D. (1997). Narcissism, Identity, and Legitimacy. The Academy of Management Review, 22, 643-686.

Colton, D., \& Covert, R. W. (2007). Designing and Constructing Instruments for Social Research and Evaluation. San Francisco: Jossey-Bass.

DiGiuseppe, R., Robin, M., Szeszko, P., \& Primavera, L. (1995). Cluster Analysis Of Narcissistic Personality Disorders on The MCMI-II. Journal Of Personelity Disorders, 9, 304-317.

Dutton, J., \& Dukerich, J. (1991). Keeping an eye on the mirror: Image and Identity in Organizational Adaptation. Academy of Management Journal, 34, 517-554.

Fromm, E. (1999). Özgürlükten Kaçış. Ankara: Öteki Publishment.

Fromm, E. (2004). Toplumsal Bilinçaltının Araştırılması. (A. Arıtan, Translate). İstanbul: Publishment.

Ganesh, S. (2003). Organizational Narcissism: Technology, Legitimacy, and Identity in an Indian NGO. Management Communication Quarterly, 16, 558-594.

Hatch, M. J., \& Schultz, M. (1997). Relations Between Organizational Culture, Identity and Image. European Journal of Marketing, 31, 356-365.

Hatch, M. J., \& Schultz, M. (2002). The dynamics of organizational identity. Human Relations, 8,115-139.

Raskin, R., \& Terry, H. (1988). A Principal-Components Analysis of the Narcissistic Personality. Journal of Personality and Social Psychology Inventory and Further Evidence of Its Construct Validity, 54, 890-902.

Ronningstam, E., Gunderson, J., \& Lyons, M. (1995). Changes in Pathological Narcissism. American Journal Of Psychiatry, 152, 253-257.

Ronningstam, E. (2005). Identifying and Understanding the Narcissistic Personality (1st Edition). Oxford University Press.

Schein, E. H. (1992). Organizational Culture and Leadership. San Francisco: Jossey-Bass.

Schuwacker, R. E., \& Lamax, R. G. (2004). A Beginner's Guide to Structural Equation Modeling; Second Edition. Londra: Lawrence Erlbaum Associates Publishers.

Streiner, D. L. (2003). Staiting at the Beginning: an Introduction to Coefficient Alpha and İnternal Consistency. Journal of Personality Assessment, 99-103.

Şimşek, Ö. F. (2007). Yapısal Eşitlik Modellemesine Giriş: Temel İlkeler ve LISREL Uygulamaları. Ekinoks Publishment: Ankara.

Tschanz, B. T., Morf, C. C., \& Turner, C. W. (1998). Gender Differences in the Structure of Narcissism: A Multi-Sample Analysis of the Narcissistic Personality Inventory. Sex Roles, 38, 863-870.

Volkan, V. (2005). Körü Körüne İnanç. Okuyan Us Publishment: İstanbul.

Whetten, D. A. (2006). Strengthening the Concept of Organizational Identity. Journal of Management Inquiry, $15,219-234$.

Yurdugül, H. Ölçme Kuramı ve Güvenrilik Katsayıları. Retrieved Octorber 10, 2008, from http://yunus.hacettepe.edu.tr/ yurdugul/3/indir/Guvenirlik.pdf 